\title{
Evaluating the EUSDR's contribution to sub-regional integration processes
}

\author{
SOAVAPA NGAMPRAMUAN \\ Ramkhamhaeng University, Bangkok \\ soavapangam@gmail.com
}

\begin{abstract}
This paper examines the dynamics of sub-regional integration processes within the Danube region as an example of EU sub-regionalism by focusing on the European Strategy on the Danube River (EUSDR). The assumption is that sub-regional integration projects differ conceptually from regional level integration processes as they tend to focus on the local and provincial level rather than the national level. As such sub-regional integration processes are characterised by integration processes based on geographic proximity, shared historical and cultural awareness, and the perception that closer local co-operation will generate economic profits. However, the regional level (EU) which represents the higher level will exert a certain influence on the occurrence and the dynamics of subregional integration processes as they are not completely independent from each other. The formulation and implementation of the EUSDR offers an insightful example in this regard.
\end{abstract}

Keywords: Danube region, EUSDR, sub-regionalism, sub- regional integration in Europe

\section{Introduction}

This paper attempts to provide a critical evaluation of the EUSDR as an integration process which, while originating mainly at the sub-regional level, is supported at the regional )or EU( level. When considering European sub-regionalism, the sub-regional integration process within the Danube River draws some thoughtful consideration, not only in its own right, but also in the context of wider integration dynamics at the regional European level. This connection to the regional, the next higher level, is not only based on geographic features, as the Danube region is situated within the European Union, interlinking some of the most prosperous parts of the European Union with some of the most underdeveloped areas. The Danube Region also has a historical legacy not only within the sub-region, but also one which connects it with the European level as well.

This intimate relationship between the sub-regional and regional level also underlines the fact that the EU decided to formulate and implement a particular sub-regional integration strategy within the Danube Region: the European Strategy on the Danube River )EUSDR(. The EU supports a macro-regional strategy for supporting the development of a particular area in addressing specific local development challenges, but with potential positive impacts for the defined area as stated in the macro-regional strategy. This macro-regional strategy, as defined by the EU, refers to an area including territory from a number of different Member States or regions associated with one or 
more common features and challenges (Schmitt et al. 2009, 4). The EUSDR actually characterises a sub-regional strategy but one which was formulated at the regional, the EU level. It incorporates comprehensive contributions from sub-regional actors focusing on supporting sub-regional economic development within a geographically defined space which includes EU member and non-member states. This shows that macro-regional strategies represent a defined policy space, trans-national in character, as is the case with sub-regional integration processes. In both cases, the geographical boundaries are flexible and subject to negotiation, dependent on the common needs and issues they are created to address. It is further stated that macro-regional strategies are designed through a bottom-up approach involving national, regional and local actors (EU COM (2016) 805 final), another similarity they share with subregional integration processes. Strengthening the co-operation among the members of a macro region focuses on the same goals sub-regional integration processes have: to support economic development by identifying and utilising local resources within an extended geographic focus. For that reason the European Council supports macro regional co-operation (EU COM (2010) 0715). However, in reality, although the regional level influence cannot be ignored or denied, the impulse to formulate a subregional integration strategy and most of its context is based on previous sub-regional and local activism involving local and sub-national actors within the Danube Region.

Methodologically, the paper draws on document analysis and a number of semistructured expert interviews with policy makers and practitioners at the local, provincial, national and EU level conducted during April 2017 (information on interviewees available in footnote). Finally, the paper also includes participatory observation via attendance at the Council of Danube Cities and Regions )CoDCR( in Ulm )26 April 2017( and conversations conducted with conference attendees.. In order to evaluate the extent to which the EUSDR can be characterised as a sub-regional integration strategy, the difference between regional and sub-regional integration processes needs to be addressed. This is the focus of the following section.

\section{Regional versus sub-regional integration: identifying key differences}

Sub-regionalism is associated with a number of characteristics. Those include geographic proximity, shared cultural and social characteristics and a common history )Acharya 2000(. Cihelkova and Hnat )2006(, Gebhard )2013( and Cottey )2009( state that the term sub-region refers to a limited geographical space, but one which can still be trans-national in character, while Dwan )2000(, Hook and Kearns )1999( point towards sub-regionalism's multilevel local, regional, national actor engagement. What's more, the actors involved come from a variety of political, business and social backgrounds. As a consequence, this array of different actors generates a complex web of co-operation and partnership between different administrative levels and actors, one which is characterised by its bottom-up nature.

However, differentiating sub-regionalism from regionalism is no easy task as they are not mutually exclusive, dichotomous concepts, and academic research has not kept a distinctive differentiation between the concepts. Manoli )2012(, for example, used both terms alternatively for describing inter-state, cross-border cooperation. Hook and Kearns )1999, 6( also argue that it is difficult to clearly distinguish between regionalism 
and sub-regionalism, because at times both terms are used interchangeably to describe cooperation between the state and trans-border activities. Adding to this challenge is the fact that the term sub-region is not exact, since the definition of any sub-region )like that of a region( reflects not only geography, but also history and politics, often making definition of space contentious.

Even so, one characteristic difference is that sub-regional integration processes tend to be less formal and institutionalised than regional integration schemes, as pointed out by Chen )2000, 7(. Consequently, developmental sub-regionalism tends to be characterised by lower levels of institutionalised even if they are involved in multilateral sub-regional cooperation with national governments, foreign ministries and other state bodies such as non-central governments, like city or provincial governments and, non-state actors such as businesses and civil society organisations. However, Dwan )2008, 81( suggests that the dynamic of regulated processes of interactions between the various actors, even when they have a wide variety of backgrounds, will support a closer co-operative relationship. Breslin and Hook )2002( state that the only aspect which differentiates sub-regionalism from regionalism is that sub-regionalism tends to focus on the smaller scale and on lower levels of government issues.

The term sub-region refers to a geographic-political space which is a sub-set of a larger regional area. Sub-regional integration dynamics are usually less formal and institutionalised than regional integration projects. Sub-regional integration processes are more likely to emerge from the local or provincial level, including local business organisations and city-to-city cooperation. It is worth remembering that sub-regional integration processes often focus on the economic trade-offs closer co-operation may offer, like the building of additional infrastructure to support the local, and often transnational, flow of goods. A better sub-regional connection may also attract foreign direct investment as well, further contributing to economic development, as stated by Bremner and Bailes )1998, 147(. Thus, developmental sub-regionalism may be associated with a response to economic underdevelopment and may require practical economic cooperation to support economic development.

To sum up, we can identify a number of characteristics of developmental subregionalism related to cross-border cooperation in economic development, education, transport, tourism, culture, science and technology, environment, organised crime and border management. Thus, the prospect of common challenges and possible gains from cooperation may generate an integration dynamic at the sub-regional level )Dangerfield 2014, 25(.

Yet, if we speak of sub-region, we also have to speak of region, of which a sub-region is a part, so as to identify particular local and provincial factors, that is factors below the national level, supporting sub-regional integration processes. After all, since a subregion is part of something larger, i.e. the region, it will have a potentially considerable impact on sub-regional integration processes, especially if formal, state-level, decision making is required.

In the case of the Danube region, the wider region within the Danube region is part of European Union. Cottey )2009, 247( offers a good example as he identifies Europe as a region within the world, while sub-regional refers to a geographic, reasonably 
coherent, area embedded within that wider region. Such an interpretation is quite appropriate in the case of the Danube region and the context that Europe provides.

The widely held belief in academic analysis of the EUSDR is that, depending on geographic proximity, the expectations of generating economic development through better infrastructure connectivity between territorial parts of different countries is confirmed. As such, the EUSDR is related to the sub-regional integration process base on cross border cooperation in economic development, transport, tourism, culture, environment and cross border security management. In order to clearly understand the dimensions and the dynamic of EUSDR, a more comprehensive analysis is required.

\section{The Danube Region: an outline}

The Danube region represents an enlarged geographic area with the Danube River as its heart. At $2850 \mathrm{~km}$, it is Europe's longest river. The Danube Region includes Germany )Bavaria and Baden-Württemberg(, Austria, the Czech Republic, Slovakia, Hungary Croatia, Slovenia, Serbia, Bulgaria, Romania, Moldova, and Ukraine. The Danube can also be differentiated into specific sections. The upper Danube area, encompassing two German Länder, Austria and Slovakia. The central Danube area, which includes Hungary, Croatia and Serbia )to Belgrade(, and the section of the Danube from Belgrade to its delta in the Black Sea area, including additional parts of Serbia, and the Danube Delta in the South Eastern part of Ukraine and Rumania.

In addition to geographic proximity, another source for sub-regional integration processes can be identified in historical and cultural legacies within a particular area. This also applies to the Danube region. Interview partners, such as Roland Arbter, current EUSDR National Coordinator of Austria, 1 and Peter de Martin, Secretary General of the Working Community of the Danube Regions, 2 also stressed this historical legacy in the context of the Habsburg Empire and with reference to other German speaking local kingdoms within the Danube's upper and middle sections. Peter de Martin observes that the German language is widely understood within the Danube region, and German is taught to almost $40 \%$ of schoolchildren in Romania. Dr. Erhard Busek3, former Special Co-Coordinator of the Stability Pact for South Eastern Europe and present Chairman of the Institute for Danube Region and Central Europe, also emphasised that the Danube region is characterised by a long history of bilateral as well as multilateral cooperation efforts. He added that even though the Danube region had witnessed periods of separation over its long history, the people living along its banks were always connected by the river and its tributaries, consequently connecting people of different cultural backgrounds throughout the centuries.

It should not be overlooked that the Danube region receives its historical and contemporary relevance from the fact that the Danube represents a crucial waterway running eastwards through Central and Eastern Europe and subsequently forming the

\footnotetext{
${ }^{1}$ Roland, Arbter. EUSDR National Coordinator of Austria Federal Chancellery. Interview by author. Tape recording. Department IV/4 - Spatial Planning and Regional Policy, Vienna, $14^{\text {th }}$ April, 2017, 9.30 am.

2 De Martin Peter, Secretary General of the Working Community of the Danube Regions in Lower Austria. Interview by author. Tape recording. Vienna, 18th April 2017, 2pm

3 Busek Erhard, Former Austrian vice-chancellor and Special Coordinator of the Stability Pact for South Eastern Europe (Brussels-based position 2002- 2008). Interview by author. Tape recording. Ulm, 26th April, 2017, 4pm
} 
Danube sub-region. However, regional coherence of the Danube region is challenged by the enormous diversity in political, sociocultural and economic terms which exist within the region. 4 For example, there are huge economic differences, as the Danube region incorporates some of the richest )e.g. Bavaria, Austria( and poorest areas )Bulgaria and Romania( of the EU, marking a considerable development gap within the sub-region. According to Czakóa, Feketeb and Poreiszc )2014, 163( an analysis of economic differences among the EUSDR member countries reveals a large disparity, especially in terms of employment rates, industrial development and regional economic development in general. This regional economic underdevelopment is linked to the separation during the Cold War period and supported by actual data on development in Slovakia, Hungary, Romania and Bulgaria in Eastern Europe. However, the parts of the Danube region which belonged to Western Europe during the Cold War, such as Austria and the southern German provinces of BadenWürttemberg and Bavaria, are ranked at the top within the Danube region.

Although a strong historical connection between the different peoples and cultures within the Danube region did exist for centuries, the Cold War division, which separated the upper section of the Danube region from the middle and lower sections, generated a lingering division between the Western countries )West-Germany and Austria( and the now post-communist countries of Hungary, Slovakia, Czech Republic, Romania, and Bulgaria. The violent break-up of the former Yugoslavia did not help either. Nevertheless, while the geo-political division no longer exists, the difference in economic development between the former Eastern and Western parts of Europe endures within the Danube region.

For Koller )2013(, reinventing the Danube as a common geographical reference point for people living in close vicinity of the river may be the opportunity to build a new awareness of belonging. According to the interviews, there is a possibility that the framework of the EUSDR could generate in people's minds a set of common aspects of identity, a kind of 'Danube consciousnesses'. This is a sentiment also shared by Riedel 5 who argued that geographic proximity and historical and contemporary awareness of belonging to the wider Danube region underlined this early support for regional integration. Aust )2014, 7( also argues that historically the riparian states of the Danube River have been closely linked to each other since the 16th century, as the Middle European section of this region was embedded in the Habsburg Empire until the beginning of the 20th century )Aust 2014, 7(.

\section{Describing the EUSDR}

The EU decided to announce a macro-regional strategy for the Danube region, the EUSDR, in 2010. The EUSDR's focus includes 14 member countries of the entire Danube Basin, including part of the river catchment area, rather than just the ten states located along the Danube River itself. These are the nine EU Member States: Germany, representing Baden-Württemberg and Bavaria, and Austria, both longtime EU members, whereas Bulgaria, Croatia, Czech Republic, Hungary, Rumania, Slovenia and Slovakia are new EU countries. Non-members are Bosnia and Herzegovina, Montenegro and Serbia, though they are candidate countries, whereas the Republic of

\footnotetext{
${ }^{4}$ Schicker, Rudolf, Coordinator for Agenda 10. Interview by author. Tape recording. EU-Strategie für den Donauraum Institutionelle Kapazität und Kooperation Kirchberggasse. Vienna, 13th April 2017, 10am 5 Riedel Arno, Head of Unit III.3a, EU Macro-Regional Strategies Federal Ministry for Europe, Integration and Foreign Affairs. Interview by author. Tape recording. Vienna, 13th April 2017, 3pm
} 
Moldova and Ukraine )in particular the oblasts of Odessa, Uschhorod, IvanoFrankiwsk and Czernowitz( are neighboring countries with no immediate plans to join the EU. At the time, it was the second macro-regional strategy the EU had developed, after the macro regional strategy for the Baltic Sea Area )EUSBR( in 2009.

The EU document on macro regions states that a macro region is characterised by a grouping of regions that principally share a common functional context in which the priorities and objectives set out in the corresponding strategy can be properly addressed )European Union Strategy for the Baltic Sea Region, 2009(. As stated in official EU documentation, the EUSDR is recognised as a unique integrated framework to address common challenges faced by a defined geographical area. The documentation further states that macro-regional strategies are designed through bottom-up approaches involving national, regional and local actors )On the implementation of EU macro-regional strategies, 2016(, another similarity they share with sub-regional integration processes. Strengthening co-operation between the members of a macro region focuses on the same goals as sub-regional integration processes, principally in support for economic development by identifying and utilising local resources within an extended geographic focus. For that reason, the European Council supports macro regional co-operation )European Union Strategy for Danube Region, 2010(.

Macro-regional strategies cover a defined policy space, transnational in character, as is the case with sub-regional integration processes. In both cases, the geographical boundaries are flexible and subject to negotiation, depending on the needs and issues that they are created to address. Yet, instead of speaking of a sub-regional strategy, the EU prefers to use the terminology of a macro-regional strategy even though the similarities between them are more than evident. According to academic work on regional integration processes, the macro regional strategy actually represented subregional strategy, and Samecki )2009( reminds us that there is no standard definition for describing a macro-region.

The essential element in a macro-regional strategy is the action plan which offers a platform for implementing cross-border projects )European Union Strategy for the Baltic Sea Region, 2009(. The structure of the action plan is then transformed into pillars and further divided into priority areas, and finally relevant indicative projects are identified. The action plans will be implemented and financed by partners other than the EU Commission )Impact Assessment Summary, European Strategy for the Danube Region, 2010(. In order to support the development of the Danube region and to strengthen cross-border sub-regional cooperation the EUSDR is based on four pillars divided into twelve distinctive Priority Areas )PAs(: The four pillars are:

1. Connecting the Danube Region. This pillar aims to improve mobility and multimodality through )a( inland waterways $) \mathrm{b}$ ( road, rail and air links; to encourage more sustainable energy; and to promote culture and tourism, people to people contacts

2. Protecting the environment in the Danube Region. This pillar aims to restore and maintain the quality of waters; to manage environmental risks; and to preserve biodiversity, landscapes and the quality of air and soils

3. Building prosperity in the Danube Region. This pillar aims to develop the knowledge society through research, education and information technologies; 
to support the competitiveness of enterprises, including cluster development; and to invest in people and skills

4. Strengthening the Danube Region. This pillar aims tTo step up institutional capacity and cooperation; to work together to promote security and tackle organised and serious crime )Com 2010 (.

The task of implementing Priority Areas )PAs( is devolved to member countries, two countries for one PA )European Union Strategy for Danube Region, 2010 (.

Selecting such an approach contributes to and supports a stronger and more cooperative engagement between EUSDR member countries since two of them share responsibility for taking care of one Priority Area. The expected positive impact on cross-border cooperation dynamics was confirmed by interview partners. As Krauchenber 6 pointed out most projects are actually cross-border projects bringing people and the economy together in order to facilitate a regional integration dynamic.. As a result, EUSDR includes territory from 14 different countries associated with one or more common geographic, cultural or economic features and challenges in the Danube Region.

When considering developmental sub-regional integration processes within the Danube region, the EUSDR can serve as an instrument of monitoring and coordinating between different countries, to support activities and policies which should be of benefit to the whole region even when being carried out in differing parts of the Danube region. The EUSDR offers the chance to present an overview of local and sub-regional processes and projects to policy makers. The EUSDR can also trigger discussion at the national level within the national context of individual member states. However, the EUSDR does not aim at higher levels of economic integration, such as achieving a union as described by classic integration theory. Instead, it offers a pragmatic solution to address local and provincial level challenges, by increasing trade and the facilitation of highly interlinked production networks. Infrastructure development at the subregional level represents another particular focus. In all of those aspects the EUSDR confirms a sub-regional approach.

Furthermore, developmental sub-regionalism seeks to address local but trans-border resource challenges, infrastructure projects or, on a more general level, sub-regional economic development. All interview partners emphasised that good inter-regional connections are key to addressing the development challenge within the Danube region. Consequently they support a sub-regional integration dynamic which will contribute to closer cooperation at different administrative levels within one country or between different countries at the local and provincial levels. The European Council meeting on 13 April 2011 concluded that the EUSDR should provide the concerned Member States and participating third countries in the Strategy with continuous assistance and guidance on good practices in cross-border, transnational and interregional coordination and implementation.

\footnotetext{
${ }^{6}$ Krauchenberg Georg, Managing Director of IDM. Interview by author. Tape recording. The Institute for the Danube Region and Central Europe (IDM), Vienna, 19th April 2017, 10am
} 


\section{The EUSDR: regional vs. sub-regional factors}

The macro regional strategy of the EUSDR is a newly integrated framework for supporting territorial integration of a limited space within the EU, differentiated from integration processes between EU Member States and third countries in the same geographical area (Dubois et al 2009, 4).

From the previous sections, the indications are that sub-regional integration dynamics within the Danube Region are inspired by regional level processes, like the formulation of the EUSDR at the EU, the regional level. This in turn would suggest the strong influence of the regional level on developments within the sub-regional level. Yet this section challenges such an interpretation, not only by highlighting that there already existed strong support for sub-regional integration within the Danube region at various local levels, but indeed, that the formulation of the EUSDR can be traced back to those earlier, local and provincial level, activities, which will be discussed below after the processes at the regional level have been evaluated. This in turn further supports the argument that we can describe the EUSDR as an example of a sub-regional integration process, even if the EU prefers the term macro-regional strategy terminologically.

\section{The regional level: influence and interest}

The formulation of the EUSDR in 2010 indicates the EU's role as an active actor in creating and supporting a sub-regional co-operation process along the Danube river basin. From a theoretical perspective, this implies that the regional level exercised its influence on sub-regional integration processes as the European Commission was mandated to assist and facilitate EUSDR members with the creation of a proposal for a comprehensive development strategy for the Danube region. For sure, the EUSDR framework does provide a comprehensive framework for the integration of fragmented sectoral activities which already occurred earlier at the sub-regional, local and provincial, level, creating a meaningful and targeted effort towards Danube-wide economic and political development. However, the EUSDR also offers the EU a platform to engage with non-members as well, like Serbia, Bosnia and Herzegovina, Montenegro, the Republic of Moldova and Ukraine.

What's more, establishing a close infrastructure network between member and nonmember states, from the Black Sea to the central and westerns parts of the EU, would contribute not only to a closer cooperation between non-member and member states, but also to a closer co-operation between members, and consequently support EU internal cohesion as well. Hence, one may interpret the establishment of the EUSDR as a new symbol of European regionalism to strengthen the unity of Europe and contribute to a change of the 'mind-set' of actors at various administrative levels from a narrow inward looking one to an outward,-out looking, sub-regional one, consequently facilitating further co-operation across policy-fields and administrative levels and countries.

For example, in 2009, the Interim Commissioner Samecki stated that macro-regions tackle functional challenges in a region with the same geographic characteristics )Samecki 2009(. The EU Commission also speaks in favour of the benefits delivered by macro-regional strategies, such as strengthened economic cooperation and stronger social and territorial cohesion )Concerning the European Union Strategy for the 
Danube Region, 2013(. Consequently, EUSDR might also be interpreted as a dynamic tool for Europeanisation, as a transformation management and facilitating device for new member states in order to offer the means for politicisation and socialisation into the EU system. Thus, for the EU, the EUSDR process offers a favourable opportunity to create a unified mechanism to push forward integration and enlargement policies. Hence, from an EU perspective, the formulation of the EUSDR does provide a new level of engagement with one of its important sub-regions and in turn provides the EU with a special role in this sub-regional integration process.

As Koller )2015, 52( states, with regards to macro-economic strategies, a new form of territorial cooperation and integrated framework was developed and now forms part of the current dynamics of EU regional policy. While Gänzle and Kern )2016, 13( argue that EU macro-regional strategy encompasses multi-level governance of national, regional and local actors, this in turn has the potential to constitute an intermediate level of governance between the EU and the national level. Agh )2015, 33( offers a similar argument by pointing out that the EU might use the dynamic of macro regional strategies to promote regionalisation within a smaller circle of neighboring countries to support trans-national cooperation but one which is institutionally much more loosely organised. The increasing impact and relevance of macro-regional strategies for supporting cooperation and economic development within a defined geographic space is also highlighted by the European Commission. As such, macro-regionalism takes on a more relevant role in European Territorial Cooperation. The European Parliament's Committee on Regional Development emphasised a sustainable framework for cooperation in order to work together with cross-border organisations across the region )Hahn 2010 (.

It can be seen that the EU played a crucial role in accelerating and facilitating processes within the Danube Region as a powerful external actor at the regional level. As such, a clear strategic interest in the formulation of a macro-regional strategy from the regional level can be identified, suggesting regional level strategic interests in subregional integration processes with the EUSDR to be interpreted as a regional level policy initiative to support the specific interest of the regional level.

However, such a regional level perspective should be partially disputed by an alternative perception that the origins of sub-regional development within the Daube region and the formulation of the EUSDR framework can be tracked back to local and provincial level initiatives, especially in some parts of Austria and Germany.

\section{The sub-regional origin of the EUSDR process}

Among the local actors that supported a Danube region wide cooperation early on are the Austrian provinces of Lower Austria and Vienna )which do have provincial status(. Well established arguments within the sub-regional integration discourse, like geographic proximity and historical awareness of connectivity, underlined the interest in sub-regional co-operation. Such motivations for supporting sub-regional integration within the Danube region were also confirmed by interview partners like Riedel7 who is currently National Coordinator of the EUSDR of Austria. For example, the long-term governor of Lower Austria )1982-1991(, Ludwig, took the first steps to initiate sub-

7Riedel Arno, Head of Unit III.3a, EU Macro-Regional Strategies Federal Ministry for Europe, Integration and Foreign Affairs. Interview by author. Tape recording. Vienna, 13th April 2017, 3pm 
regional cooperation as early as during the Cold War period when Europe and the Danube region were still politically and economically divided. Even as this early support favoured a Danube region wide co-operation, most supported projects were local, following local initiatives in addressing local challenges. De Martin8 pointed out that Ludwig also supported the active involvement of national government actors in order to facilitate closer local and regional co-operation by raising awareness of regional activities. However, De Martin insisted that locally based working groups were more active than government level cooperation.

However, the political leader of Lower Austria was not the only early supporter of a Danube wide regional integration process. Dr. Busek9 and Mr. Langer ${ }^{10}$, general coordinator and spokesperson of CoDCR, stated that Mayor Gönner of Ulm was another driving force for a Danube regional integration process. They said that Mayor Gönner had long believed that the cities and countries of the Danube Region needed to be more active in promotion and co-operation so as to have a bigger voice at the European level. He initiated the process of discussion and conversation amongst the cities and countries of the Danube, which led to the Ulm Declaration in 2009 and subsequently the formal formation of the Council of the Danube Regions. Ulm is a town located at the upper section of the Danube and part of the German province of BadenWuerttemberg. Geographically, Baden-Wuerttemberg is where the Danube River originates from the Black Forest. Once again, historical connections play an important role as many people from this province, collectively described as Danube Swabians, emigrated between the 17th-19th centuries from the upper section of the Danube to its middle and lower sections, todays southern Hungary, the Banat, Serbia, and Romania. This strong historical relationship, still highly relevant today, as pointed out by Langer and Busek, contributes to a strong contemporary economic cooperation, with Baden-Wuerttemberg becoming one of the leading economic partners within the Danube Region with some 500.000 people from the Danube region working for German companies located in Baden-Wuerttemberg. Langer added that this economic cooperation also includes strong economic links with local SMEs, for instance in Temesware and Timisoara )Romania( )Langer personal communication, April 27th 2017 .

Local and provincial political support generated local level cooperation dynamics within the Danube sub-region. Peter de Martin ${ }^{11}$,for example, points towards the Danube Cooperation Process )DCP( which was initiated in 1992, or to the ARGE Donauländer, a working community at the local level but with a regional wide focus as indicated by its membership, initiated by the provincial government of Lower Austria during the early 1990s. One important focus of the ARGE which contributes to regional development is to bring local/regional business actors together by providing information and arranging activities so that local people can identify business opportunities within the Danube Region. Peter de Martin adds that the provincial

\footnotetext{
${ }^{8}$ De Martin Peter, Secretary General of the Working Community of the Danube Regions in Lower Austria. Interview by author. Tape recording. Vienna, 18th April 2017, 2pm

9 Busek Erhard, Former Austrian vice-chancellor and Special Coordinator of the Stability Pact for South Eastern Europe (Brussels-based position 2002- 2008). Interview by author. Tape recording. Ulm, 26th April, 2017, 4pm ${ }^{10}$ Langer Peter, General coordinator of the Council of Danube cities and regions, Director of the European Danube Academy. Interview by author. Tape recording. Ulm, 27th April, 1pm

${ }^{11}$ De Martin Peter, Secretary General of the Working Community of the Danube Regions in Lower Austria. Interview by author. Tape recording. Vienna, 18th April 2017, 2pm
} 
governor, Ludwig, also supported the ARGE's 'bottom-up' strategy for facilitating local interests for Danube region integration dynamics.

Historically, working communities were part of the original strategy of supporting Danube region wide integration within a region which was divided by the Cold War. Through the fall of the Iron Curtain and the related political-economic changes after 1989, cooperation along the Danube region become more common. However, working communities such as the ARGE Donaulaender still represent a valuable form of cooperation since they offer a strategic approach to achieving cooperation at different levels, including the local, provincial and even national level. In doing so, they bring together a community of people with different political, economic and administrative backgrounds. Riedel ${ }^{12}$, De Martin13 and Schicker ${ }^{14}$ confirmed in their interviews that within the ARGE an emphasis is placed on bottom-up processes when identifying projects and, seen in retrospect, this has contributed considerably to the development of the EUSDR. This observation also offers an indication of the impact earlier local level cooperation had on the EUSDR formulation process.

Another early approach to local and sub-regional cooperation can be identified in the cooperation of the Council of the Danube Cities and Regions )CoDSR( which was launched in Ulm with the "Deklaration der Donaustädte" on 4 July 1998. The CoDCR is a major inter-municipal and interregional network and became a good example of cross-border cooperation in the Danube Region. Its political Head Office in Ulm and operational Headquarters and General Secretariat in Bucharest, represent a bridge that links European, regional and local institutions with academic, business, and financing networks as well as representatives of civil society. Schwetz ${ }^{15}$, Counsellor of the Senate of the City of Vienna, points out that CoDR also acts as an umbrella for regional and local authorities in Hungary, Bulgaria, Romania, and Serbia and consequently as a mayoral level co-operation network with respect to the EUSDR process. Hence, CoDCR offers another good example of locally inspired cooperation which supports a sub-regional integration process within the Danube Region. As stated by Riedel geographic proximity and historical and contemporary awareness of belonging to the wider Danube region underlined this early support for regional integration.

Another influential effort in supporting the integration process within the Danube Region was created with the Danube Cooperation Process )DCP( in 2002 which should become very influential in generating the EUSDR process. The DCP was formally launched in Vienna on 27 May 2002 with the adoption of the Declaration by the European Commission and the 13 participating countries of the Danube Basin. Busek 16 who was one of the founders of the EUSDR and the aforementioned Schwetz17, who is also the Chairman of the Pan-European Transport Corridor VII, the

\footnotetext{
12 Riedel Arno, Head of Unit III.3a, EU Macro-Regional Strategies Federal Ministry for Europe, Integration and Foreign Affairs. Interview by author. Tape recording. Vienna, 13th April 2017, 3pm

13 De Martin Peter, Secretary General of the Working Community of the Danube Regions in Lower Austria. Interview by author. Tape recording. Vienna, 18th April 2017, 2pm

${ }^{14}$ Schicker DI Rudolf, Coordinator for Agenda 10. Interview by author. Tape recording. EU-Strategie für den Donauraum Institutionelle Kapazität und Kooperation Kirchberggasse. Vienna, 13th April 2017, 10am

${ }_{15}$ Schwetz Otto, Counsellor of the Senate of the City of Vienna. Interview by author. Tape recording. Austrian Association of Cities and Towns City Hall of Vienna (Rathaus). Vienna, 19th April, 4pm

${ }^{16}$ Busek Erhard, Former Austrian vice-chancellor and Special Coordinator of the Stability Pact for South Eastern Europe (Brussels-based position 2002- 2008). Interview by author. Tape recording. Ulm, 26th April, 2017, 4pm ${ }^{17}$ Schwetz Otto, Counsellor of the Senate of the City of Vienna. Interview by author. Tape recording. Austrian Association of Cities and Towns City Hall of Vienna (Rathaus). Vienna, 19th April, 4pm
} 
Danube, claim that the EUSDR was actually inherited from the Danube Cooperation Process )DCP( even though no one currently works on it. According to Busek, Austria and Romania presented the draft for a Danube Strategy which was to become the "the forum for multi-lateral consultation on Danube Strategy matters" )South-East Cooperation Initiative (at the third and final meeting of foreign ministers of the DCP in 2007.

However, the German land of Baden-Wuerttemberg was also a strong supporter. It provided Danube affairs a platform in Brussels, as as early as 2006, this initiative originated in the para-diplomatic efforts of Baden-Württemberg's subnational government, organising a series of conferences in Ulm from 2006 onwards which included governmental representatives from the Danube Countries in Brussels. The conference purpose was to strengthen the European dimension of the region in both the media and among the public )Busek, personal communication, April 26th 2017(. Then, in October 2008, the EU Commissioner for Regional Policy launched the first steps toward the development of the Danube Strategy - in close consultation with Romania, Austria, and Germany )in particular Bavaria and Baden Wuerttemberg( and supported by Serbia.

The Final Declaration of the 2009 Ulm Danube Summit identified the challenges that Baden-Wuerttemberg believed an EU strategy for the Danube region should address. They included competitiveness, growth and prosperity in the transport sector, energy security and environmental protection to protect the Danube region as an eco-system, and a focus on culture for promoting good-neighborly relations between the countries of the region )Langer ${ }^{18}$, personal communication, April 27th 2017(. Thus, the Ulm City Summit had a significant impact in advancing the decision to create the EUSDR.

The EU's Committee of the Regions founded an interregional Danube group in 2010. This group tabled an initiative on a Danube Strategy to the Commissioner for Regional Policy. Langer states that following the 2009 elections to the European Parliament, a Danube Forum to monitor and complement the further development of the strategy was eventually created. The Forum invited the Commission to present an EU strategy for the Danube region by the end of 2010.

Taken as a whole, all of the local but Danube region wide initiatives, and the existence of bottom-up networks prior to the formulation of the EUSDR can be said to have contributed to regional-wide dynamics of cooperation which in turn was then formalised into the EUSDR framework. This had an impact on the EUSDR as well, contributing to its character as a bottom-up sub-regional integration dynamic. The lasting impact of pre-existing local initiatives on the EUSDR has also been confirmed by various interview partners, including Dr. Busek, Langer, and Marco ${ }^{19}$.

\section{Conclusions}

\footnotetext{
${ }^{18}$ Langer Peter, General coordinator of the Council of Danube cities and regions, Director of the European Danube Academy. Interview by author. Tape recording. Ulm, 27th April, 1pm

19 Marco Onida, EU Coordinator of EUSDR to all members. Interview by author. Tape recording. Competence

Centre Macro-regions and European Territorial Cooperation, Avenue de Beaulieu 5. Brussels, Belgium, 21th April, $9.30 \mathrm{am}$
} 
This paper evaluated the challenges in distinguishing between regional and subregional integration processes by focusing on the European Strategy for the Danube Region. The EUSDR was selected because it offers a valuable example, since a first impression would suggest it was formulated at the regional level. Thus, this paper offers another approach to further strengthening EU internal cohesion by providing specific support for a particularly defined geographical space as well as offering the opportunity of engaging with non-member countries and in doing so supporting a process of socialisation with EU institutions and processes. Consequently, interpreting the EUSDR as a regional approach for strengthening regional level influence seems quite appropriate.

However closer observation of how the EUSDR process was conceptualised offers a quite different impression, one which points towards a sub-regional integration process, founded and encouraged at the local and provincial level. This constitutes a bottom-up process in which the interests of local and provincial level stakeholders, such as the Council of the Danube Cities and Regions and local working groups especially from Germany and Austria were involved. This process is based on various factors which are associated with sub-regional integration processes such as a shared history and culture, a common perception of belonging to a specific geographic area, and the anticipation that co-operation at the local level, which can also be transnational, will generate economic benefits at the local level. Based on those perceptions, a number of local initiatives, but with sub-regional wide focus on the Danube region, developed over a considerable period of time, even stretching back to the Cold War period during which the Danube region was separated politically and economically.

As analysed in the paper, those local co-operations, often described as working communities, offered a forum for exchange and cooperation, and over time contributed to the development of networks of local actors engaged in Danube region wide activities. Those cooperations also transcended the earlier Cold War divide and generated enough political support for a more formal sub-regional development strategy to be formulated at the regional level. These locally inspired dynamics and related integration processes also point towards another aspect generally associated with sub-regional integration processes characterised as 'bottom-up'. These are distinct from formal state-level integration processes, described as 'top-down'. Taken together, the analysis provided in the paper offers a valuable assessment of the EUSDR as a sub-regional integration process, supported by the regional level, but having its origin at the sub-regional level.

\section{Bibliography}

Acharya, Amitav. The quest for identity: International relations of Southeast Asia. Oxford: Oxford University Press, 2000.

Ágh, Attila. "The European Union Strategy for the Danube Region as a vehicle for European Renewal." In A 'Macro-Regional' Europe in the Making, edited by Stefan Gaenzle and Kristine Kern, 145-168. London: Palgrave-Macmillan, 2016.

Aust, Karsten. 'Understanding Macro-Regional Strategies: The EUSDR and Existing Forms of Governance and Cooperation in the Danube Region', 2014, available at 
file://E:/Download/Understanding_Macro-Regional_Strategies\%20)1(.pdf ) last accessed on 14 November 2017 (

Bremner, Ian and Alyson Bailes. "Sub-regionalism in the Newly Independent States." International Affairs 74, no.1 )January 1998(: 131-147. https://doi.org/10.1111/14682346.00009.

Breslin Shaun and Hook Glenn D. "Microregionalism and World Order: Concepts, Approaches and Implications." In Microregionalism and World Order, edited by Shaun Breslin and Glenn D Hook, 1-22. London: Palgrave Macmillan, 2002.

Chen, Xiangming. "Both Glue and Lubricant: Transnational Ethnic Social Capital as a Source of Asia Pacific Subregionalism." Policy Sciences 33, no. 3/4 )2000(: 269287. https://doi.org/10.1023/A:1004882907559

Cihelková, Eva and Pavel, Hnát. 'Regional Integration of the New Member States during the Pre-Accession Period and after Eastern Enlargement', C.A.P. Working Paper, 2006, available at http://www.cap-lmu.de/publikationen/2006/cihelkovahnat.php )last accessed on 1 November 2017(

The Commission to The European Parliament, The Council, The European Economic And Social Committee And The Committee Of The Regions, European Union Strategy for the Baltic Sea Region, Commission of the European Communities, Communication, $\operatorname{Com}(2009) 248$ final, 2009, available at http://ec.europa.eu/regional_policy/sources/docoffic/official/communic/baltic/com _baltic_en.pdf (last accessed on 14th November 2017)

The Commission to the European Parliament, the Council, the European economic and social committee and the committee of the regions, European Union Strategy for Danube Region, European Commission Brussels, 8.12.2010 COM (2010) 715 final Communication, 2010, available at http://eur-lex.europa.eu/legalcontent/EN/TXT/PDF/?uri= CELEX:52010DCo715\&from =EN ( last accessed 15th November 2017)

The Commission to the European Parliament, the Council, the European Economic and social Committee and the Committee of the regions European Union Strategy for the Danube Region, Impact Assessment Summary, European Strategy for the Danube Region, European Commission Brussels, 8.12.2010 SEC (2010) 1489 final Commission staff working document action plan Accompanying document to the communication, 2010, available at http://ec.europa.eu/smartregulation/impact/ia_carried_out/docs/ia_2010/sec_2010_1491_en.pdf. (last accessed: 14th November 2017).

The Commission to the European Parliament, the Council, the European Economic and Social Committee and the Committee of the Regions. European Commission, Report Concerning the European Union Strategy for the Danube Region, COM (2013) 181 final, 2013, available at file://C:/Dokumente\%2ound\%2oEinstellungen/ploberger/Eigene\%2oDateien/Dow nloads/EU-Report-on-EUSDR.pdf (last accessed on 14th November 2017) 
The Commission to the European Parliament, The Council, The European Economic And Social Committee And The Committee Of The Regions, Report on the implementation of EU macro-regional strategies, Com (2016) 805, 2016, available at file:

http://ec.europa.eu/regional_policy/sources/cooperate/macro_region_strategy/pdf /report_implem_macro_region_strategy_en.pdf (last accessed on o5 November 2017)

Cottey, Andrew. "Sub-regional Cooperation in Europe: An Assessment." Bruges Regional Integration \& Global Governance Paper 3, 2009, available at http://www.cris.unu.edu/fileadmin/workingpapers/BRIGG_papers/BRIGG_32009__revised_version.pdf )last accessed on 16th October 2016(

Czakóa, Katalin, David Feketeb and Veronika Poreiszc. "Economic Differences of Countries by the River Danube." Procedia Economics and Finance 9 )2014(:163-175. https://doi.org/10.1016/S2212-5671)14(00017-3

Dubois, Alexandre, Sigrid Hedin, Peter Schmitt and Jose Sterling. "EU Macroregions and Macroregional Strategies - A Scoping Study." Nordregio Electronic Working Paper 4, 2009, available at https://pdfs.semanticscholar.org/d8c9/8ff9ab16389be7b4c4codbd360024e4b9e35.p df )last accessed on $15^{\text {th }}$ November 2017(

Dangerfield, Martin. "From Subregionalism to Macro-regionalism in Europe and the European Union." In A 'Macro-Regional' Europe in the Making, edited by Stefan Gaenzle and Kristine Kern, 22-46. London: Palgrave-Macmillan, 2016.

Dwan, Reanta. "Sub-regional, Regional and Global Levels: Making the Connections." In Sub-regional Cooperation and Integration in Europe, edited by Gunilla Herolf, 8196. Stockholm: Utrikespolitiska Institutet, 2000.

Hahn, Johannes. "Opening Speech: Regional Policy", Danube Strategy Conference, European Commission, 6 February 2010, available at https://ec.europa.eu/commission/commissioners/20142019/hahn/announcements/opening-remarks-commissioner-johannes-hahnpresentation-western-balkans-strategy-plenary-session_en )last Accessed on 14 November 2017.

Gänzle, S. and Kern K. "Macro-regions, 'Macro-regionalization' and Macro-regional Strategies in the European Union: Towards a New Form of European Governance?" In A macro-regional 'Europe in the Making: Theoretical Approaches and Empirical Evidence, edited by Gänzle, Stefan and Kern Kristine, 3-22. London: Palgrave Macmillan, 2016.

Gebhard, Carmen. "Sub-Regional Cooperation in Central Europe - Past, Present and Future." Academic and Applied Research in Public and Management Science 12, no. 1 )2013(: 25-38.

Hook, Glenn D and Ian Kearns. Subregionalism and World Order. London: Palgrave Macmillan, 1999. 
Koller, Boglarka. "Danube identity in reflection to the emerging new narrative in the EU." In Proceedings Conference on the EU Strategy for the Danube Region:

Challenges and Chances 2014 - 2020 )04 - 06 November 2013(, edited by Franziska Sielker and Katja Vonhoff, available at https://www.danuberegion.eu/attachments/article/616542/DSRN_Conference_Proceedings_2015.pdf )last accessed on 14 November 2017(

Manoli, Panagiota. The Dynamics of Black Sea Sub-regionalism. Farnham: Ashgate Publishing Ltd, 2012.

Samecki, Pawel. Macro-regional strategies in the EU - A Discussion Paper presented by Comissioner Pawel Samecki in Stockholm at 18 September 2009, available at http://ec.europa.eu/regional_policy/archive/cooperation/baltic/pdf/macroregional_s trategies_2009.pdf (last accessed on 12 March 2018) 